\title{
Flexible bronchoscopy in the management of congenital lobar emphysema in the neonate
}

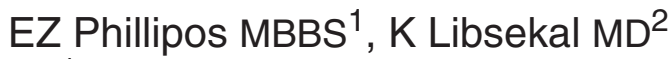 \\ ${ }^{1}$ Division of Newborn Medicine, \\ Children's Health Centre, University of Alberta Hospital, Edmonton; \\ ${ }^{2}$ Queen Elizabeth Hospital, Grande Prairie, Alberta
}

\begin{abstract}
EZ Phillipos, K Libsekal. Flexible bronchoscopy in the management of congenital lobar emphysema in the neonate. Can Respir J 1998;5(3):219-221.

This paper describes the case of a $3 \mathrm{~kg}$ neonate who had congenital lobar emphysema of the left upper lobe (LUL). He was in severe respiratory distress with a fraction of inspired oxygen of 0.8 . Chest $x$-ray showed hyperlucent expanded left hemithorax and marked mediastinal shift. Following flexible bronchoscopy and introduction of ultrathin bronchoscope into the LUL bronchus, symptoms and chest $\mathrm{x}$-ray improved markedly. Flexible bronchoscopy resulted in emergency relief of his initial respiratory distress, and left upper lobe lobectomy was performed electively three days later.
\end{abstract}

Key Words: Congenital lobar emphysema, Flexible bronchoscopy, Neonate

\section{Bronchoscopie flexible dans la prise en charge de l'emphysème lobaire congénital du nouveau-né}

RÉSUMÉ : Le présent article décrit le cas d'un nouveau-né de $3 \mathrm{~kg}$ atteint d'un emphysème lobaire congénital du lobe supérieur gauche. Le bébé accusait une détresse respiratoire sévère ; la fraction d'oxygène du gaz inspiré $\left(\mathrm{FIO}_{2}\right)$ était de 0,8 . La radiographie thoracique a révélé une zone d'hyperclarté et de distension de l'hémithorax gauche, avec refoulement médiastinal. À la suite d'une bronchoscopie flexible et de l'introduction d'un bronchoscope très mince dans la bronche du lobe supérieur gauche, les symptômes et le cliché thoracique se sont nettement améliorés. La bronchoscopie flexible a permis de soulager rapidement la détresse respiratoire initiale du nouveau-né, et une lobectomie du lobe supérieur gauche a pu être pratiquée de façon élective trois jours plus tard.
$\mathrm{C}$ ongenital lobar emphysema (CLE) is a rare but important cause of respiratory distress in the newborn period. It was first described by Nelson (1) in 1932, and Gross and Lewis (2) performed the first successful lobectomy in 1945. Nearly half of the patients are symptomatic in the first few days of life (3), with tachypnea, dyspnea and cyanosis as the most predominant symptoms. Diagnosis of CLE is easily diagnosed by a plain chest radiograph. Computed tomography scan and ventilation/perfusion (V/Q) lung scanning may also be helpful (4).

The role of flexible bronchoscopy in the diagnosis and management of CLE is controversial (5-7), despite the fact that more than 50\% of CLE is caused by an intrinsic bronchial abnormality (5). We present a case of CLE in a newborn infant involving the left upper lobe; flexible bronchoscopy had a major role in the diagnosis and management.

\section{CASE PRESENTATION}

A $3 \mathrm{~kg}$ male full term neonate was born spontaneously; he had Apgar scores of 8 and 9 at 1 and 5 mins, respectively. At 15 mins of age he became tachypneic with mild cyanosis requiring oxygen. Initial chest x-ray indicated 'wet lungs'. 


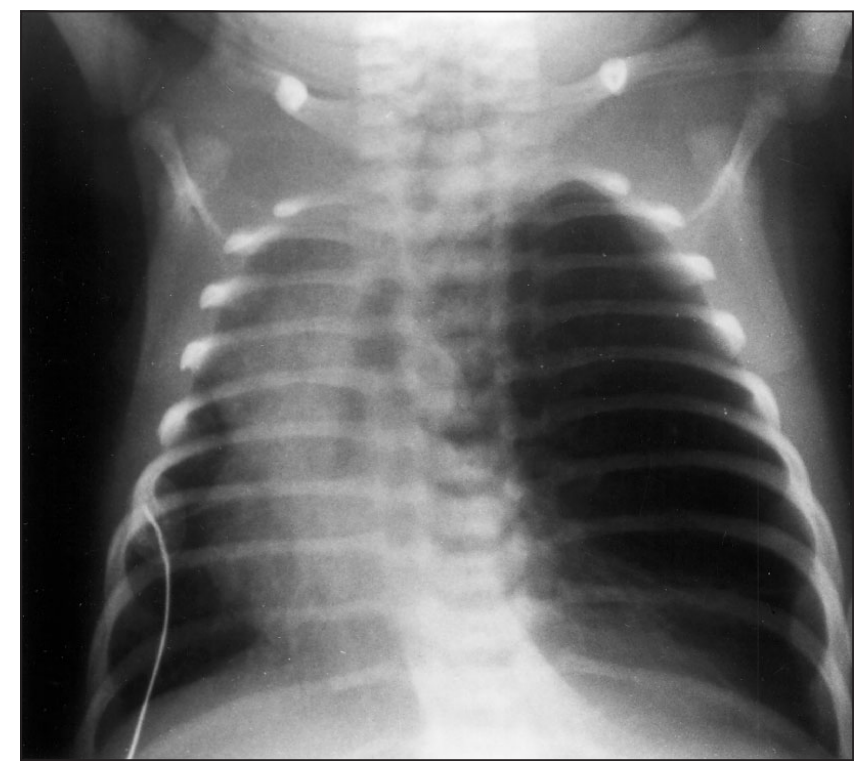

Figure 1) Chest $x$-ray on day 9 demonstrating marked hyperlucency of the left hemithorax, mediastinal shift to the right and flattened left hemidiaphragm

Subsequent chest X-rays showed evolution of CLE of left upper lobe (LUL). By nine days of age he was in marked respiratory distress requiring a fraction of inspired oxygen $\left(\mathrm{FiO}_{2}\right)$ of 0.8, and x-ray (Figure 1) showed marked hyperlucency of left lung, mediastinal shift and a flattened left hemidiaphragm. At bronchoscopy using ultrathin brochoscope (2.2 $\mathrm{mm}$ ), the LUL bronchus was noted to be slit-like. However, the slit opened slightly on inspiration and closed completely on expiration, demonstrating an expiratory check valve LUL bronchial obstruction. The tip of bronchoscope was then pushed into the LUL bronchus, resulting in a sudden gush of air escaping through LUL bronchus. This led to marked improvement in the infant's condition and x-ray study (Figure 2), as well as a decrease in the oxygen requirement $\left(\mathrm{FiO}_{2}=0.3\right)$. The bronchoscopic appearance suggested bronchial cartilage hypoplasia. LUL lobectomy was performed electively three days after bronchoscopy, and histology confirmed broncial cartilage hypoplasia. The infant was discharged home eight days after surgery.

\section{DISCUSSION}

CLE is easily diagnosed by a plain chest $\mathrm{x}$-ray. However, establishing the etiology of CLE requires further investigation. In approximately $50 \%$ of cases of CLE the etiology is unknown, and in the remaining $50 \%$ an identifiable cause of bronchial obstruction is found $(5,8)$. Review of the literature from 1990 to 1996 identified 36 cases presenting in the neonatal period (4-7,9-14). The etiology of CLE in these cases were as follows: $19(53 \%)$ unknown, seven (19\%) polyalveolar lobe, three (8\%) bronchial stenosis, three $(8 \%)$ bronchial cartilage deficiency, two (6\%) pulmonary artery aneurysm, one (3\%) segmental bronchomalacia and one (3\%) membranous bronchial septum. It is unclear how many of the unknown etiology group (53\%) underwent bronchoscopy.

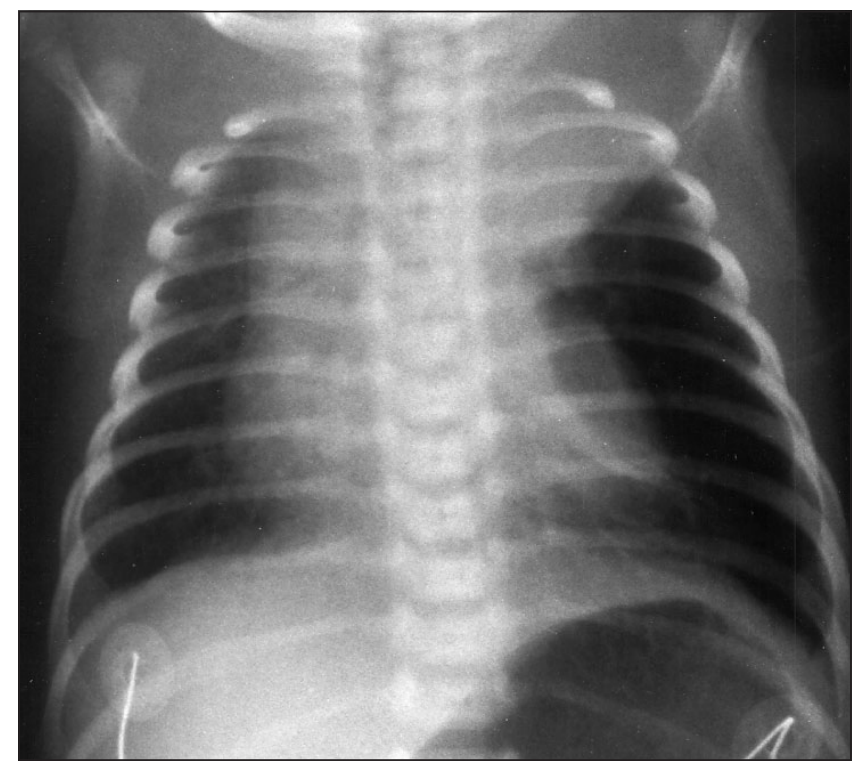

Figure 2) Chest $x$-ray on day 9 immediately following flexible bronchoscopy demonstrating marked improvement, with decrease in hyperlucency of left hemithorax, return of the heart and mediastinum to a more central position and partial collapse of $L U L$

However, in 10 of the 36 cases (28\%), the etiology of CLE was established by bronchoscopy. This together with the present case make us strongly believe that flexible bronchoscopy can play a major role in establishing the etiology of CLE. In some conditions such as bronchial cartilage deficiency, pulmonary artery aneurysm and segmental bronchomalacia flexible bronchoscopy is clearly superior to other diagnostic investigations in demonstrating airway dynamics (15) and pathology.

Establishing the correct etiology of CLE is of paramount importance in choosing the treatment modality. Traditional treatment of CLE has been lobectomy in the majority of cases following a plain chest radiograph $(7,12)$. Karapurkar et al (12) concluded that lobectomy was the only treatment for CLE. However, recently several reported cases were managed conservatively $(4,5,9)$ with improvement in symptomatology and V/Q scans (4). In some cases in which the etiology was established at bronchoscopy (two of 10 cases reviewed above), the treatment is clearly not lobectomy, but resection of a bronchial membranous septum (13) and prolonged continuous positive airway pressure for segmental bronchomalacia (9). Hence, flexible bronchoscopy, by establishing the correct etiology of CLE, helps decide the treatment modality and may avoid unnecessary lobectomy. Finally, another benefit of flexible bronchoscopy is demonstrated in this case. Following bronchoscopy all symptoms were temporarily relieved and hyperinflation of LUL disappeared, thus allowing elective rather than emergency surgery.

\section{CONCLUSIONS}

Flexible bronchoscopy has a role in the diagnostic workup and direction of treatment in patients with CLE. In addition, it may relieve hyperinflation of lung lobe, secondary to bronchial cartilage hypoplasia or segmental bronchomalacia. 


\section{REFERENCES}

1. Nelson RL. Congenital cystic disease of the lung. J Pediatr 1932;1:233.

2. Gross RE, Lewis JE. Defect of the anterior mediastinum. Surg Gynecol Obstet 1945;80:549-54.

3. Buckner DM. Congenital lobar emphysema. Clin Perinatol 1978;5:105-13.

4. Kennedy CD, Habibi P, Matthew D, Gordon I. Lobar emphysema: Long term imaging follow-up. Radiology 1991;180:189-93.

5. Stigers KB, Woodring JH, Kanga JF. The clinical and imaging spectrum of findings in patients with congenital lobar emphysema. Pediatr Pulmonol 1992;14:160-70.

6. Kaklikkaya I, Zengin M, Özdemir R, Yavas D, Özcan F. Congenital lobar emphysema. A case report. J Cardiovasc Surg 1994;35:359-61.

7. Nuchtern JG, Harberg FJ. Congenital lung cysts. Sem Pediatr Surg 1994;4:233-43.

8. Leape LL, Longino L. Infantile lobar emphysema. Pediatrics 1964;34:246-55.

9. Sagy M, Silver P, Nimkoff L, Zahtz G, Amato JJ, Bierman FZ. Pediatric intrathoracic large airway obstruction: Diagnostic and therapeutic considerations. Pediatr Emerg Care

1994;10:351-8.

10. Cleveland RH, Weber B. Retained fetal lung liquid in congenital lobar emphysema: a possible prediction of polyalveolar lobe. Pediatr Radiol 1993;23:291-5.

11. Richards DS, Langham MR, Dolson LH. Antenatal presentation of a child with congenital lobar emphysema. J Ultrasound Med 1992;11:165-8.

12. Karapurkar SA, Dorkar JD, Birmole BJ. Malformation of lung in neonates (lobectomy for congenital lobar emphysema and lung cyst). J Postgrad Med 1993;39:224-7.

13. Saim L, Mohamad AS, Ambu VK. Congenital lobar emphysema: A case with bronchial septum. Int J Pediatr Otorhinolaryngol 1994;28:241-6.

14. Okabe K, Hara K, Ando A, et al. Congenital lobar emphysema successfully treated by right upper lobectomy at five hours after delivery: a case report. Kyobu Geka 1992;45:590-4.

15. Doull IJM, Connett GJ, Warner JO. Bronchoscopic appearances of congenital lobar emphysema. Pediatr Pulmonol 1996;21:195-7.

\section{Smoking: An uncommon research topic}

Smoking is harmful to the lung and heart but chest physicians and other doctors do not study the effects of smoking sufficiently. About eight years ago, an article reported that only $1.2 \%$ and $3.7 \%$ of the abstracts of the 1988 and 1989 European Respiratory Congresses, respectively, referred to the harmful consequences of smoking (2). Our new study examined whether physicians perform research concerning smoking.

Physicians' research activity on smoking was studied through the abstracts of three 1996 respiratory congresses in Europe, the United States and Greece $(3,4,5)$. Table 1 demonstrates that only $1.8 \%$ of the abstracts in annual meeting of the American Thoracic Society and 4\% in European Congresses referred to smoking. The number of abstracts about bronchial asthma exceeded those about smoking by seven times at the American, six time at the European and about five times at the Greek congresses. Abstracts referring to tuberculosis were more numerous than abstracts referring to smoking at all three congresses in 1996. In the European Congress about $50 \%$ of studies concerning smoking were epidemiological. At the annual meeting of the American Thoracic Society the majority were clinical studies (Table 2).

The disappointing results of our study showed that there is little smoking-related research by physicians worldwide. Other subjects such as tuberculosis and asthma - minor public health problems compared with smoking - are more com-

\section{REFERENCES}

1. Gourgoulianis KI. Smoking: The need for further medical studies. J Natl Cancer Inst 1989:81:1668. (Lett)

2. Abstracts of Annual Congress of European Respiratory Society, Stockholm sweden, September 7 to 11, 1996.
TABLE 1

Smoking research presented at respiratory congresses, 1996

\begin{tabular}{lccc}
\hline & $\begin{array}{c}\text { Hellenic } \\
\text { Thoracic } \\
\text { Society } \\
\text { meeting }\end{array}$ & $\begin{array}{c}\text { European } \\
\text { Respiratory } \\
\text { Society } \\
\text { meeting }\end{array}$ & $\begin{array}{c}\text { American } \\
\text { Thoracic } \\
\text { Society } \\
\text { meeting }\end{array}$ \\
\hline Subject & $4(1.8 \%)$ & $101(4 \%)$ & $91(1.8 \%)$ \\
Pollution & $3(1.3 \%)$ & $77(3.1 \%)$ & $58(1.2 \%)$ \\
$\begin{array}{l}\text { Bronchial } \\
\text { asthma }\end{array}$ & $25(11.1 \%)$ & $458(18.5 \%)$ & $639(12.8 \%)$ \\
Lung cancer & $40(17.8 \%)$ & $114(4.6 \%)$ & $74(1.5 \%)$ \\
Chronic & $14(6.2 \%)$ & $216(8.7 \%)$ & $201(4 \%)$ \\
$\quad$ bronchitis & $20(8.9 \%)$ & $114(4.6 \%)$ & $226(4.5 \%)$ \\
Tuberculosis & 225 & 2478 & 4982 \\
Total & & & \\
\hline
\end{tabular}

mon in medical research. If physicians studied smoking better, they could contribute to antismoking campaigns more effectively.

KI Gourgoulianis MD G Krommydas MD

A Arseniou MD

PA Molyvdas MD

University of Thessaly, School of Medicine Larissa, Greece

3. Abstracts of American Thoracic Society Annual Meeting, New Orleans, Louisiana, May 11-14, 1996.

4. Abstracts of 8th Annual Congress of Hellenic Thoracic Society, Athens, Greece, 1996. 


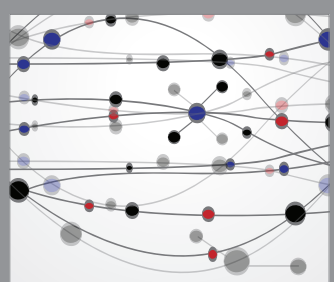

The Scientific World Journal
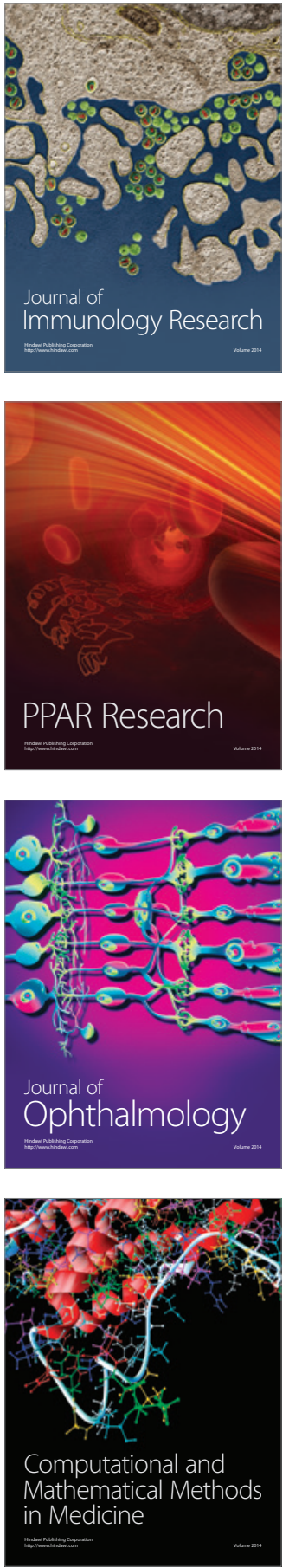

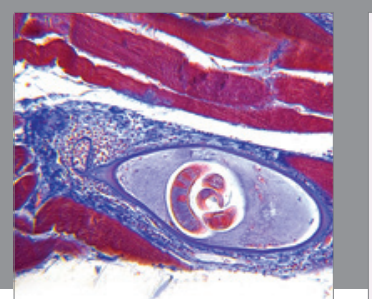

Gastroenterology Research and Practice

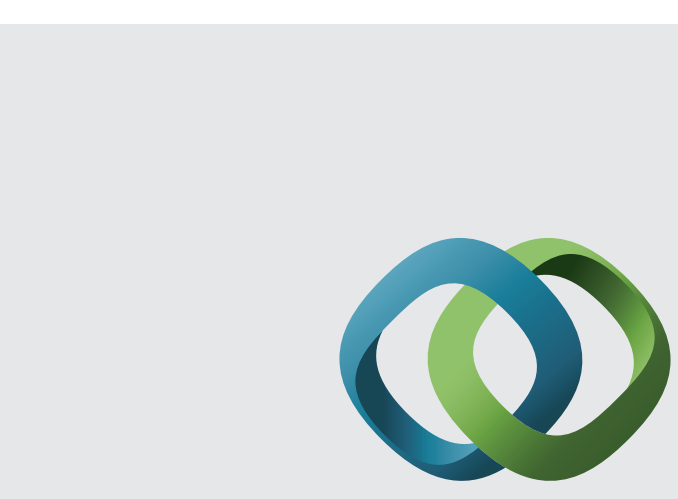

\section{Hindawi}

Submit your manuscripts at

http://www.hindawi.com
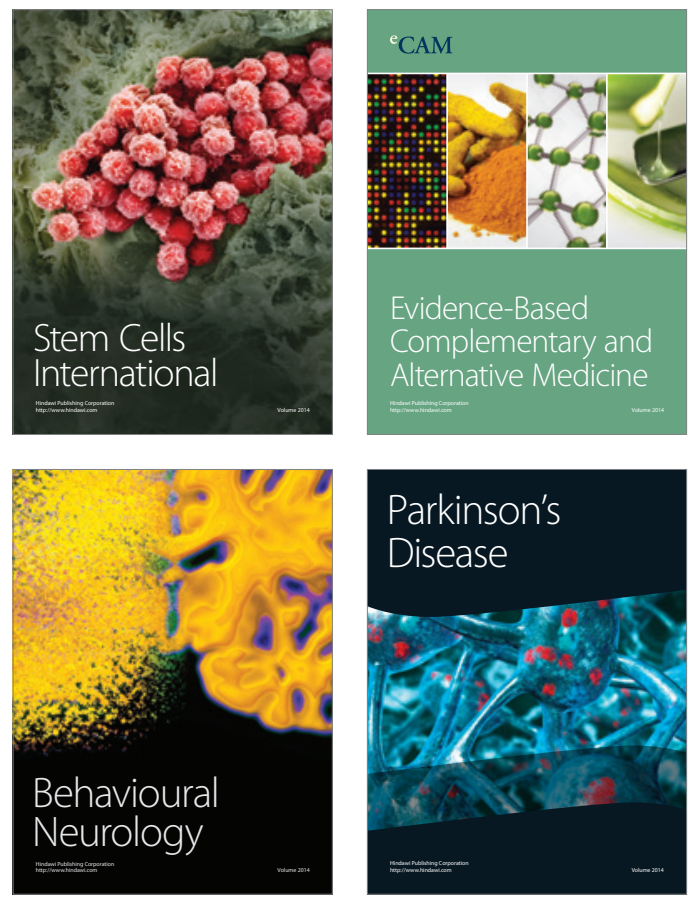
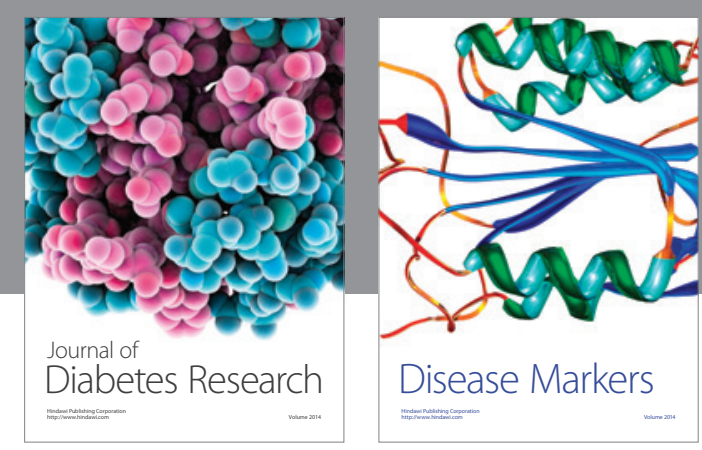

Disease Markers
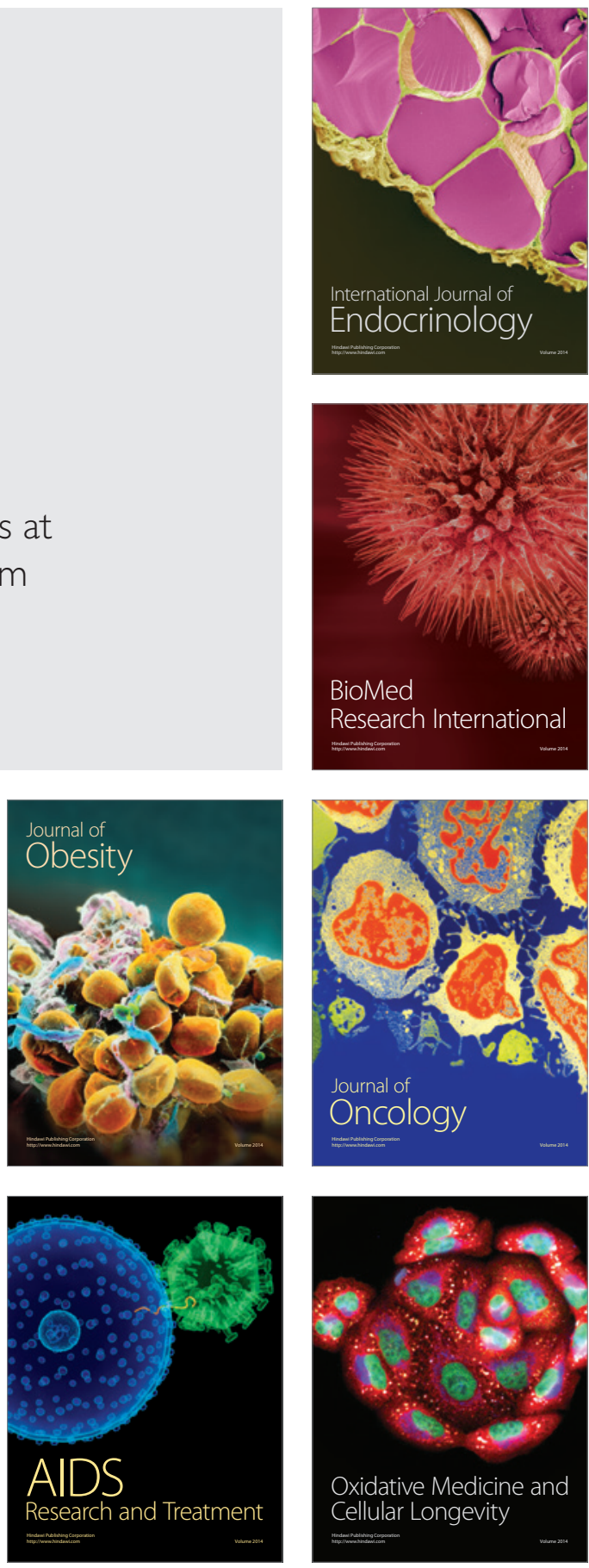